\title{
A CARROÇA E O TREM: FLANNERY O'CONNOR E A LITERATURA SULISTA NORTE-AMERICANA
}

\section{THE WAGON AND THE TRAIN: FLANNERY O'CONNOR AND AMERICAN SOUTHERN LITERATURE}

\author{
Débora Ballielo Barcala \\ Universidade Estadual Paulista em Assis, Unesp, Assis, SP, Brasil \\ Cleide Antonia Rapucci \\ Universidade Estadual Paulista em Assis, Unesp, Assis, SP, Brasil
}

\begin{abstract}
Resumo: O presente artigo pretende discutir a posição ambígua ocupada pela escritora estadunidense Flannery O’Connor (1925-1964) na comunidade literária sulista norteamericana. Sua condição de mulher branca a colocava nessa posição ambígua, pois, enquanto branca, era participante da classe dominante de sua regiáo, mas, enquanto mulher, era oprimida. Para isso, baseamos nosso trabalho em Sarah Fodor (1996), Katherine Prown (2001) e Sarah Gordon (2003). Depois, são feitas consideraçôes sobre a recepção e a fortuna crítica da obra da autora nos Estados Unidos, para demonstrar como sua obra resiste a rotulaçóes, apesar de ter sido interpretada das mais diversas maneiras.
\end{abstract}

Palavras-chave: Flannery O'Connor; literatura sulista norte-americana; escrita de autoria feminina.

Abstract: This work aims to discuss the ambiguous position occupied by the American writer Flannery O'Connor (1925-1964) in the Southern literary community. Her condition as a white woman put her in this ambiguous position because as white she was part of the dominant social class, but as a woman she was oppressed. To do that, this article was based in Sarah Fodor (1996), Katherine Prown (2001) and Sarah Gordon (2003). Later, some considerations about the author's reception in the United States are presented to demonstrate how her work resists labeling despite having been interpreted in several different ways.

Keywords: Flannery O'Connor; American Southern literature; female authorship.

Nascida em 25 de março de 1925, em Savannah, Geórgia, nos Estados Unidos, Mary Flannery O’Connor começou sua carreira literária efetivamente ao matricular-se no programa de escrita criativa em Iowa, em 1945. A partir de então, a autora publicou sua dissertação de mestrado composta por seis contos, intitulada The Geranium: A Collection of Short 
Stories (1947), duas coletâneas de contos, A Good Man Is Hard to Find (1955) e Everything That Rises Must Converge (1965), e dois romances, Wise Blood (1952) e The Violent Bear It Away (1960). A maior parte de sua obra foi escrita em Milledgeville, Geórgia, na fazenda Andalusia, onde viveu na companhia de sua mãe e das aves que criava (em especial, pavôes), já que sua mobilidade fora limitada em consequência do lúpus (doença crônica autoimune da qual seu pai fora vítima). A doença, porém, não a impediu de escrever até mesmo no leito do hospital, onde revisou alguns dos últimos contos de sua segunda coletânea, publicada postumamente. Em 3 de agosto de 1964, aos 39 anos de idade, O'Connor faleceu em decorrência de complicaçóes pós-cirúrgicas da retirada de um tumor fibroide que reativou o lúpus e propiciou uma infecção renal.

Em sua palestra "Some Aspects of the Grotesque in Southern Fiction", proferida na Wesleyan College, em Macon, Geórgia, Flannery O'Connor comenta que a dificuldade de ser um escritor no Sul dos Estados Unidos é grande, já que há muitos bons escritores na região. $\mathrm{O}$ fato de todos escreverem sobre a mesma conjuntura social faz com que o escritor tenha de tomar cuidado para "não fazer mal àquilo que já foi feito em sua completude" (O’CONNOR, 1988, p. 818, tradução nossa). Ela também comenta que a presença de William Faulkner, no cenário literário da região, faz toda a diferença "naquilo que o escritor pode e não pode permitir a si mesmo fazer. Ninguém quer sua carroça parada no mesmo trilho em que a Dixie Limited está avançando" ('O'CONNOR, 1988, p. 818, tradução nossa).

Embora O'Connor enxergasse Faulkner como um trem veloz que poderia atropelar a carroça de escritores sulistas menores, incluindo ela mesma,

O Oxford Companion to Women's Writing in the United States afirma que "O'Connor atrai a atençáo crítica de mais acadêmicos a cada ano do que qualquer outra escritora americana do século vinte”. Em outras palavras, ela é a equivalente feminina do grande escritor do Mississippi, e seu companheiro sulista William Faulkner² (JORDAN, 2005, p. 50, tradução nossa).

\footnotetext{
1 "The presence alone of Faulkner in our midst makes a great difference in what the writer can and cannot permit himself to do. Nobody wants his mule and wagon stalled on the same track the Dixie Limited is roaring down".

2 "The Oxford Companion to Women's Writing in the United States notes that "O'Connor attracts the critical attention of more scholars each year than any other twentieth-century American woman writer." In other words, she is the female equivalent of the great Mississippi writer and her fellow Southerner William Faulkner".
} 
Essa comparação, no entanto, é bastante problemática e não queremos afirmar a importância da obra de O'Connor na literatura americana colocando-a como a "equivalente feminina" de um autor americano consagrado e vencedor de um prêmio Nobel, pois isso seria reforçar a postura e os padróes literários machistas nos quais a própria autora se via inevitavelmente enredada. É inegável, conforme nos informa Gordon (2003), que O’Connor sofreu influência de Faulkner em seus primeiros rascunhos. No início do desenvolvimento de seu estilo, a escritora tentou criar um fluxo de consciência parecido com o do autor. "Ela foi astuta o suficiente, no entanto, para perceber que deveria avançar, que seu estilo deveria ser próprio" (GORDON, 2003, p. 202, tradução nossa). Logo, apesar de admirar a obra de Faulkner, a fala sobre ele demonstra a angústia da autora em ter seu trabalho sempre comparado e pautado por padróes masculinos.

Ao falar sobre sua própria trajetória literária, O’Connor menciona que, quando começou a escrever, foi logo classificada como pertencendo à School of Southern Degeneracy (Escola da Degeneração Sulista, em tradução nossa). Ela afirma: "cada vez que eu ouvia sobre a Escola da Degeneração Sulista, eu me sentia como Brer Rabit preso na boneca de piche"3 (O'CONNOR, 1988 , p. 814, tradução nossa $)^{4}$. No manuscrito ${ }^{5}$ de uma versão anterior à palestra publicada como "Some Aspects of the Grotesque in Southern Fiction", O’Connor menciona também que, algum tempo depois, alguns críticos enquadraram sua obra em algo chamado "O Culto do Grotesco Gratuito", que ela considerou como algo ainda mais degradante, posto que não era

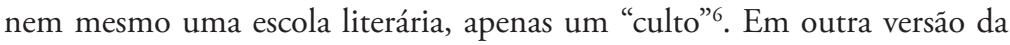
palestra, desta vez posterior à versão publicada, a autora menciona que sua obra tem sido chamada de gótica, algo que considera um insulto, já que o gótico, para ela, usa o excesso e a morbidez por eles mesmos, sem um

\footnotetext{
${ }^{3}$ Brer Rabbit é um personagem popular no sul dos Estados Unidos. Brer Rabbit, ou Brother Rabbit é "malandro" e provoca as autoridades e desrespeita os padrốes morais. Em uma de suas histórias, alguém faz uma boneca de piche para enganar Brer Rabbit, que, quando a vê e sente-se ignorado, resolve bater na boneca; mas, quanto mais ele bate e tenta se livrar, mais preso na boneca fica.

4 "When I first began to write, my own particular bête noire was that mythical entity, The School of Southern Degeneracy. Every time I heard about the School of Southern Degeneracy, I felt like Brer Rabbit stuck on the tar-baby" (O'CONNOR, 1988, p. 814).

5 Manuscritos não publicados consultados no acervo da biblioteca Ina Dillard Russel, na Georgia College and State University, em Milledgeville, Geórgia.

${ }^{6}$ Arquivo 203a da coleção de Georgia College.
} 
sentido moral mais profundo ${ }^{7}$.

Por esses exemplos, podemos notar que O'Connor resistia às classificaçóes que procuravam dar à sua obra, principalmente porque acreditava que sua ficção era primordialmente católica. No entanto, ela mesma conseguiu aceitar a classificação de grotesca, como sua palestra sobre o tema parece demonstrar. Ainda em "Some Aspects of the Grotesque in Southern Fiction", a autora faz menção ao panfleto I'll Take My Stand, um manifesto pró-Sulista, publicado por um grupo de escritores, poetas, ensaístas e romancistas com raízes no Sul dos Estados Unidos em 1930. Acredita-se que esse grupo, chamado de Agrários ou Fugitivos, teve grande influência na obra de O'Connor, principalmente após sua ida para o curso de escrita criativa em Iowa.

De acordo com Prown (2001), John Crowe Ransom e Allen Tate (os principais nomes dos Fugitivos/Agrários) tiveram um papel fundamental na emergência de uma escrita e crítica sulistas no século XX. Enquanto críticos e editores, mais do que como escritores, os Agrários "ajudaram a lançar as bases do que mais tarde viria a ser chamado de 'Southern Literary Renaissance"” (PROWN, 2001, p. 25, tradução nossa). A estudiosa defende que os princípios teóricos e estéticos de Flannery O’Connor originaram-se, em grande parte, do pensamento desses escritores. No entanto, conforme nos informa Sarah Gordon (2003), O'Connor não tinha o hábito de ler a obra dos escritores Agrários, tendo lido a já mencionada obra I'll Take My Stand apenas no último ano de sua vida. A autora conhecia pessoalmente vários dos Agrários, como John Crowe Ransom, Robert Penn Warren, Andrew Lytle, Allen Tate e Caroline Gordon, mas não apreciava a obra deles particularmente.

Portanto, a influência do grupo pode ter se dado através de seu papel importante na disseminação e na institucionalização de discursos norteadores da escrita sulista moderna e na formulação de teorias gerais de interpretação literária. Um dos principais objetivos dos Agrários era substituir a idealização da mulher (identificada como uma tendência do século XIX) pela "primazia do intelecto masculino e da masculinidade branca sulista" (PROWN, 2001, p. 26, tradução nossa). Ao ligar os princípios da literatura romântica do século anterior com uma audiência majoritariamente feminina, os Agrários procuraram fundar uma nova estética, que negasse o Romantismo e rejeitasse o feminino.

7 Arquivo 248a da coleção de Georgia College.

8 "primacy of the male intellect and of white southern manhood". 
Assim, com o objetivo de chocar uma audiência feminina e, ao mesmo tempo, atrair uma audiência masculina mais racional e "capaz de apreciar a arte verdadeira" (PROWN, 2001, p. 28, tradução nossa), o grupo apostava em imagens gráficas de sexualidade e morte, frequentemente fetichizando a morte de mulheres. De acordo com Prown (2001), eles procuravam substituir a adoração da beleza e da virtude femininas por imagens de corpos corrompidos de mulheres, trocavam referências idealizadas das plantations por descriçóes cínicas da vida industrializada das cidades e, ao invés de descrever os negros como trabalhadores diligentes e satisfeitos que colaboraram na construçáo da civilização, optavam por fazer referência às origens clássicas da civilização anglo-europeia. Dessa forma, apesar do seu objetivo declarado de construir uma nova estética, os Agrários acabaram por reforçar, ainda mais, a posição tradicional da literatura centralizada na cultura europeia e de exclusão do negro e da mulher.

Portanto, para fazer parte desse panorama crítico e literário, Prown (2001) acredita que Flannery O'Connor não teria outra opção senão

abraçar uma tradição estética construída sobre a premissa contraditória de que, ao mesmo tempo em que poderia reivindicar subjetividade com base em seu status como branca, teria que negar qualquer forma de subjetividade baseada em seu status como mulher ${ }^{9}$ (PROWN, 2001, p. 32, tradução nossa).

Para Ransom, um dos líderes dos Agrários, a arte e a literatura deveriam ser avaliadas de acordo com seu grau de ligaçáo ou representação da experiência do "homem intelectual adulto" e, consequentemente, uma mulher que quisesse avaliar a literatura de forma objetiva e científica deveria incorporar uma persona masculina. No círculo dos Agrários/Fugitivos, uma mulher escritora era uma grande contradição, já que seria o objeto da arte "reivindicando uma subjetividade que a natureza nega a ela e da qual a civilização a protege" (PROWN, 2001, p. 36, tradução nossa).

A despeito de sua aversão por mulheres escritoras, o grupo dos Agrários contribuiu no desenvolvimento da carreira de várias mulheres de letras sulistas, como Katherine Anne Porter, Eudora Welty, Caroline Gordon e, é claro, Flannery O'Connor. Os Agrários usaram sua influência como críticos e editores de vários jornais importantes (Kenyon Review, Sewanee Review,

\footnotetext{
9 "embrace an aesthetic tradition constructed on the contradictory premise that, while she might claim subjectivity on the basis of her whiteness, she would have to deny any formof subjectivity grounded in her femaleness".
} 
Southern Review) para promover o trabalho de escritoras, já que queriam, de forma geral, promover o trabalho de escritores sulistas no país.

Mas o apoio do grupo tinha limitaçôes. Apesar de divulgar as autoras, os Agrários relutavam em considerar sua arte tão digna de atenção crítica quanto a obra de um homem, e o número de resenhas sobre a obra de escritoras publicadas em suas revistas era bastante inferior ao de peças de ficçâo ou poesia. A posição paternalista e condescendente desses críticos parecia ser a de julgar que as escritoras precisavam de sua ajuda, mas nunca chegariam ao status de colegas escritoras ou críticas; "Em resumo, embora os Fugitivos/Agrários fossem generosos em seu apoio a certas escritoras, o apadrinhamento do grupo se estendia sem violar significativamente as hierarquias que caracterizavam discursos dominantes" (PROWN, 2001, p. 64, tradução nossa).

Prown (2001, p. 64, tradução nossa) defende ainda que essa lógica dos papéis de gênero, típica do período e que se refletia também na literatura, deixava apenas duas opçóes para escritoras como O'Connor: "permanecer satisfeita com o status de segunda-classe ou trabalhar para criar um cenário ficcional aparentemente sem gênero com a esperança de ganhar atenção crítica mais séria". A estudiosa acredita que Flannery escolheu a segunda opção, pois criou uma ficção que não só se posicionava avessa às mulheres, como também reiterava a hierarquia constituída, o que proporcionou maior divulgação de seu trabalho, bem como a consagraçáo dele pela crítica.

Embora náo acreditemos que a ficçáo de Flannery seja misógina, como Prown parece supor, é possível que ela tenha adequado sua escrita a um padrão mais masculino de literatura, influenciada talvez pela recepção e crítica de um dos romances mais célebres da Geórgia, Gone with the Wind, de Margaret Mitchell. Sucesso de público, um best-seller sulista, o romance de Mitchell pode ter sido uma influência ambivalente para a então adolescente O'Connor. Se, por um lado, o estrondoso sucesso do romance dava esperança a mulheres aspirantes a escritoras, por outro, "o romance foi censurado por sua popularidade e sua interpretação distorcida da história sulista" (GORDON, 2003, p. 210, traduçáo nossa). Enquanto a população em geral esperava um novo Gone with the Wind de cada escritora sulista, a crítica literária passou a desprezar o romance, que trazia em sua narrativa uma visão dos papéis de gênero na figura de Scarlett O'Hara, uma mulher não-convencional para a época. Assim, de certa maneira, o romance pode ter sido um exemplo do que uma escritora não deveria fazer se quisesse ter sua obra aceita pela crítica. 
Sarah Fodor, em seu artigo intitulado "Marketing Flannery O'Connor: Institutional Politics and Literary Evaluation" (1996), contesta essa visão bastante difundida, de que a fama da autora deve-se à sua conformação aos princípios dos Agrários e dos New Critics $^{10}$. Fodor afirma que sua pesquisa

\begin{abstract}
mostra, ao contrário, que embora o New Criticism tenha sido uma influência importante na recepção de O'Connor, nem o poder desse grupo institucionalmente dominante, nem aquele de uma "universidade americana" monolítica é explicação suficiente para seu status canônico. Antes, a academia veio a considerar O'Connor importante no curso de um diálogo cultural mais amplo sobre como caracterizar sua ficção: como parte da cultura popular ou de elite, sulista ou universal, religiosa ou diabólica, masculina ou feminina ${ }^{11}$ (FODOR, 1996, p. 12-13, tradução nossa).
\end{abstract}

Fodor náo ignora o fato de que os contatos que O'Connor estabeleceu em Iowa tenham sido importantes para sua carreira literária; ela chega mesmo a afirmar que foram essas conexóes que permitiram que a autora tivesse contos publicados em um número de antologias, como a coleção $\mathrm{O}$. Henry, editada por Paul Engle, diretor do Iowa Writer's Workshop, que tinha ligaçôes com o grupo dos New Critics. Engle também levou New Critics sulistas como John Ransom e Robert Penn Warren para Iowa enquanto O'Connor era aluna.

Por outro lado, os contos "Everything That Rises Must Converge" e "Revelation" receberam o prêmio "O. Henry em volumes editados por Richard Poirier em 1963 e 1965. Enquanto Engle tinha conexôes com os New Critics, Poirier estava associado com os intelectuais de Nova Iorque e com perspectivas de esquerda" (FODOR, 1996, p. 15, tradução nossa). Assim, de acordo com Fodor, os intelectuais de Nova Iorque, de esquerda e marxistas, entre eles, Philip Rahv do Partisan Review, também apreciavam e publicavam o trabalho de O'Connor. Obviamente, os New Critics

\footnotetext{
${ }^{10}$ New Criticism foi um movimento formalista de teoria literária que dominou a crítica literária americana em meados do século XX. O nome do movimento deriva do livro de John Crowe Ransom, denominado The New Criticism (1941). Ransom foi o mesmo poeta e crítico já mencionado como um dos líderes dos Fugitivos/Agrários. Nesse sentido, há estudiosos que interpretam o New Criticism como uma continuação do movimento dos Agrários.

11 "shows on the contrary that although the New Criticism was one important influence in O'Connor's reception, neither the power of this institutionally dominant group nor that of a monolithic 'American university' is a sufficient explanation of her canonical status. Rather, the academy came to consider O'Connor important in the course of a wider cultural conversation about how to characterize her fiction: as part of popular or elite culture, as southern or universal, as religious or diabolical, as masculine or feminine".
} 
valorizavam a estrutura da obra de O'Connor, enquanto os intelectuais de Nova Iorque viam nela preocupaçóes socioeconômicas. Mas embora evidenciassem aspectos diferentes da obra da autora, "juntos eles ajudaram a estabelecer o trabalho dela como uma contribuição importante para a ficção americana contemporânea" (FODOR, 1996, p. 17, tradução nossa).

Assim, podemos concluir que, mesmo que, de alguma forma, Flannery O'Connor tenha sido influenciada pelos princípios literários e críticos dos Agrários em relação à estrutura e à forma, sua obra conseguiu transcender suas limitaçóes e atrair a atenção de outros públicos que não compactuavam com as ideias do New Criticism. Josephine Hendin (1970, p. 133, tradução nossa) também questiona o comprometimento de O'Connor com as ideias dos Agrários. Para ela, “a ficção de O'Connor não dispóe de um senso de interpretaçáo de passado e presente como um tradicionalista como Allen Tate considera essencial ao escritor com um sentimento em relação à sua terra-natal". Na obra da autora, o passado e o presente náo se fundem, mas estâo em constante confronto.

Diferentemente de outros escritores sulistas, o tratamento dado à história por O'Connor náo é lisonjeiro, e o sul de antes da Guerra da Secessão não é apresentado como um ideal do qual a região decaiu. De fato, O'Connor só escreve mais abertamente sobre a Guerra-Civil americana em um de seus contos "A Late Encounter with the Enemy", cujo protagonista é um veterano de guerra centenário que náo consegue se lembrar de nenhum dos acontecimentos ou motivaçóes para a guerra. Esse tratamento despendido a um dos acontecimentos mais marcantes da história do sul dos Estados Unidos é único e curioso, já que O'Connor viveu a maior parte de sua vida em Milledgeville (capital da Geórgia de 1804 a 1868, portanto durante a Guerra-Civil), cidade incendiada pelo exército da União, que marchou e tomou o palácio do Governo. A Guerra-Civil americana é ainda uma ferida aberta no sul.

Todavia, na obra de O'Connor, "o passado sulista anterior à guerra não existe como um padrão ou valor, ou mesmo como um indicador do que foi perdido, uma medida de como a vida decaiu. Ele existe como uma ficção para os idosos e crianças" (HENDIN, 1970, p. 134, tradução nossa). Esse é um dos traços distintivos da ficção da autora, senão o principal. Seu trabalho rejeita a chamada "estética da memória", que caracteriza a obra de outros autores renomados do renascimento sulista como William Faulkner, Robert Penn Warren e Eudora Welty, embora seja comumente relacionado, pelos críticos, a esses escritores (GORDON, 2003). 
Para Hendin (1970), o uso que O'Connor faz da violência em suas narrativas também é único, pois, ao invés de imbuir os atos de violência de valor simbólico e atribuir-lhes grande significância, como fazem Faulkner e Styron, O'Connor faz com que a violência praticada em suas histórias "não deixe marca alguma na consciência de qualquer pessoa" (HENDIN, 1970, p. 156, tradução nossa). Assim, para a estudiosa, O'Connor faz parte do processo de desmitificaçáo da literatura americana, processo frequentemente associado a William Carlos Williams e a Wallace Stevens. Hendin (1970) defende ainda que a obra e a trajetória de O'Connor são mais parecidas com a de Truman Capote do que com a de qualquer outro escritor sulista.

Em resumo, a obra de Flannery O'Connor tem sido difícil de categorizar desde o princípio de sua carreira literária, pois, embora apresente várias semelhanças com a obra de escritores sulistas, sua ficção apresenta também várias particularidades que tornam difícil encaixá-la em alguma das escolas estabelecidas pela academia. A própria autora defendia que, em sua época, "não há bons escritores, ligados minimamente, que seriam tão ousados a ponto de afirmar que eles falam por uma geraçáo ou uns pelos outros. Hoje cada escritor fala por si mesmo"12 (O'CONNOR, 1988, p. 813, tradução nossa). Embora O'Connor enfatize sua posição independente, ela também faz parte de uma comunidade literária da qual náo tinha ciência: o grupo das escritoras sulistas.

De acordo com Yaeger (2000), embora, à primeira vista, as mulheres escritoras do sul no século XX pareçam um grupo bastante heterogêneo, especialmente considerando-se a questáo racial e de classe social, as escritoras sulistas demonstram, através de sua obra, a convulsão da tradição em uma regiáo que reluta em aceitar mudanças. Yaeger (2000) acredita que a abordagem mais difundida sobre literatura escrita por mulheres no sul é redutora, pois defende que as escritoras queriam apenas retratar a tragédia da vida, evidenciando o pessimismo e a capacidade humana para praticar o mal, além de demonstrar a decadência da história e da regiáo.

Ela propóe, por outro lado, analisar o quanto as escritoras sulistas tinham de subversivo em sua escrita, mesmo aquelas mulheres que, em sua época, permaneceram à margem do cânone e da crítica. Para Yaeger (2000, p. xiii, tradução nossa), "o grotesco é onipresente na ficção de mulheres sulistas, não como uma filigrana decorativa, mas como um espaço de obsessão política" de escritoras negras e brancas. O grotesco surge de uma

\footnotetext{
12 "there are no good writers, bound even loosely together, who would be so bold as to say that they speak for a generation or for each other. Today each writer speaks for himself".
} 
história real de mutilação e corpos estraçalhados ocorrida no Sul; assim, os corpos desfigurados e violentados da ficção de O'Connor representam essa história de mutilação da qual o sul do século XX é herdeiro. Mas ela não é a única a abordar as contradiçóes da regiáo dessa maneira:

\begin{abstract}
Escritoras tăo diversas como Porter, Hurston, Welty, McCullers, O'Connor, Walker, Williams, Douglas, Gilchrist, e Ansa [...] produzem uma escrita vociferante que é incrivelmente responsiva ao silêncio político, linguagem corporal e obsessáo por objetos assim como a uma série de questôes ontológicas sobre direitos à cidadania e autocontrole que não atingem apenas o Sul, mas têm se espalhado pela naçáa ${ }^{13}$ (YAEGER, 2000, p. 10-11, tradução nossa).
\end{abstract}

Ainda que não soubesse, Flannery O'Connor dividia anseios literários e modos de expressão com suas companheiras escritoras, já que todas estavam inseridas no mesmo contexto sociocultural. Mesmo assim, muitos críticos ainda insistem em etiquetá-la como masculina. Se estivesse viva, talvez O'Connor ainda se sentisse como Brer Rabbit tentando livrar-se da boneca de piche de algumas classificaçóes. De todo modo, é preciso destacar que, embora se autodeclarasse católica, a autora criou um corpo literário que extrapolou os limites impostos pelos Agrários, mas ainda mantendo algo em comum com a tradição literária a ponto de ser publicada.

Nesse sentido, a escrita de O'Connor está, invariavelmente, inserida em duas culturas ao mesmo tempo: a cultura dominante masculina e a cultura das mulheres, numa posição ambivalente. Conforme afirma Showalter (1994, p. 50), "não pode haver escrita ou crítica totalmente fora da estrutura dominante; nenhuma publicação é totalmente independente das pressóes econômicas e políticas da sociedade dominada pelos homens". A escrita das mulheres consiste sempre num discurso de duas vozes, ou seja, um discurso que expressa as culturas tanto do silenciado quanto do dominante. Portanto, a "escrita das mulheres [...] está dentro de duas tradições simultaneamente" (SHOWALTER, 1994, p. 50).

É possível encontrar a voz “feminina” de O’Connor em suas narrativas na representação dos papéis de gênero da sociedade sulista de meados do século XX. Da mesma forma, é impossível negar o status canônico da

\footnotetext{
13 "Writers as diverse as Porter, Hurston, Welty, McCullers, O'Connor, Walker, Williams, Douglas, Gilchrist and Ansa [...] produce vociferous writing that is incredibly responsive to a political silence, body talk, and object obsession as well as to a series of ontological questions about rights to citizenship and self-possession that not only plague the South, but have spread throughout the nation".
} 
autora, conquistado, em parte, por seu sucesso em preencher os requisitos literários de um mercado e de uma crítica essencialmente masculinos. É a partir dessa posição ambivalente que Flannery O'Connor escreve. Mesmo apresentando características comuns a vários grupos de escritores (Agrários, masculinos, sulistas, grotescos e femininos), a obra da autora tem resistido a classificaçóes apressadas, pois O'Connor logrou avançar em sua carreira literária da simples imitação dos grandes escritores para o desenvolvimento de um estilo e de uma voz própria e inconfundível.

\section{Recepçáo e fortuna crítica nos Estados Unidos}

As influências da obra de O'Connor permanecem vivas no trabalho de outros artistas. Alice Walker, escritora também da Geórgia, que viveu parte de sua infância a poucos quilômetros de Andalusia, afirma que leu avidamente a ficção de O'Connor e reconheceu nela os contornos de sua terra natal. Em 1966, "Walker completou, mas não publicou um conto que pode ser visto como a parte que falta do conto de O'Connor 'Everything That Rises Must Converge'. Walker dedicou o conto a O'Connor” (WARREN, 2014, p. 1 , tradução nossa). Entitulado "Convergence", esse conto foi publicado pela primeira vez no Flannery O'Connor Review, no ano de 2014.

No ano de 2010, o periódico Shenandoah, um dos primeiros a publicar contos de O'Connor (“A Stroke of Good Fortune”, em 1953), comemorou o aniversário de 60 anos da revista com um volume duplo, especialmente dedicado à memória da escritora, que incluía ensaios críticos, poemas, fotografias e peças de ficçáo inspirados em sua obra. $\mathrm{O}$ volume contou com 47 colaboradores, entre eles Joyce Carol Oates, Fred Chappell, Michael Knight, Erin E. McKee e os poetas Claudia Emerson e Charles Wright.

Sua influência estendeu-se também a artistas de outras áreas que não a literatura. Músicos e bandas pop como Jimmy Buffet, U2 e Billy Bob Thornton demonstraram interesse em sua obra. No discurso de agradecimento da premiação do Grammy de 1987 de melhor álbum, a banda irlandesa U2 mencionou Flannery O'Connor. "Tanto o ator Tommy Lee Jones quanto o apresentador de talk-show Conan O'Brien escreveram trabalhos de conclusão de curso em Harvard sobre a ficção dela" (CASH, 2002, p. 320). Muitos críticos e estudiosos apontam ainda para uma influência da obra de O'Connor no trabalho do diretor de cinema Quentin Tarantino, especialmente no filme Pulp Fiction (1994), em que atua o ator Samuel L. Jackson, cujo primeiro papel no cinema foi em um curta- 
metragem chamado "The Displaced Person" (1977), uma adaptação do conto homônimo de O'Connor.

Assim, embora parte do sucesso de O'Connor deva-se a seus apoiadores intelectuais e acadêmicos, seria um erro acreditar que a obra da autora não tinha apelo popular. O'Connor também publicou em revistas não acadêmicas, principalmente por motivos financeiros. Em Mademoiselle, foi publicado, em 1948, o conto "The Capture", um dos seus primeiros, escrito ainda na pós-graduação em Iowa. Esse mesmo conto foi publicado novamente na coletânea da revista: 40 Best Short Stories from Mademoiselle, 1935-1960. De acordo com Fodor (1996), vários contos publicados em revistas populares são também alguns dos mais valorizados pela academia, como é o caso de "Good Country People", publicado na Harper's Bazaar, em 1955. A Harper's Bazaar publicou também "A Temple of the Holy Ghost", em 1954, e "The Enduring Chill", em 1958.

Fodor (1996) menciona ainda a propaganda dos livros de O'Connor e a construção de suas capas. De acordo com ela, nas capas das primeiras publicaçōes de Wise Blood e A Good Man Is Hard to Find, a ênfase era no sexo e no erotismo, de uma forma que não tinha relaçáo com o conteúdo do livro. A primeira capa de $A$ Good Man Is Hard to Find é um bom exemplo dessa tendência. A ilustraçáo escolhida para a capa do volume pretendia retratar a cena mais famosa e violenta do conto "Good Country People", na qual Manley Pointer engana a protagonista Hulga e rouba sua perna prostética, porém acaba por representar a cena como uma interação romântica característica de um filme comercial. A imagem transforma a protagonista, uma "mulher loira, de trinta e dois anos, obesa, socialmente inapta, em uma garota pin-up, de cabelos escuros, esbelta, graciosa, jovem, para divulgar o livro como um melodrama pulp ou um romance Harlequim" (FODOR, 1996, p. 18, tradução nossa). A perna de pau de Hulga, elemento fundamental na história, sequer aparece na cena. As primeiras ediçôes de O'Connor eram, portanto, divulgadas de forma sensacionalista para atrair leitores da massa. Esse padrão de marketing só se alterou no final da década de 1960, à medida que a reputaçáo de O'Connor, nos meios acadêmicos, ia tornando-se mais segura.

De acordo com Golden e Sullivan (1977), essa mudança só ocorreu a partir do ano de 1960, com a publicação de seu segundo romance, The Violent Bear It Away. Até então, embora não fosse ignorada, a ficção de O'Connor era pouco resenhada. Flannery O'Connor and Caroline Gordon: A Reference Guide menciona vinte e sete resenhas em 1955, ano da publicação 
do primeiro livro de contos A Good Man Is Hard to Find, contra cinquenta e nove apenas sobre The Violent Bear It Away. Grande parte das primeiras críticas é

[...] hostil, mas o mero fato de que O'Connor foi resenhada em periódicos de prestígio como o Kenyon Review e em revistas influentes de circulação em massa como o Time, indica que os críticos a viam como uma escritora que deveria ser levada a sério, se não necessariamente admirada ${ }^{14}$ (GOLDEN; SULLIVAN, 1977, p. 5, tradução nossa).

Prova disso é que alguns de seus contos foram selecionados para a coletânea Best American Short Stories de 1956, 1957, 1958, 1962 e 1979. De fato, O'Connor gozou de um status perante a academia que poucas de suas colegas escritoras conseguiram alcançar. Logo em 1961,

Willard Thorpe escolheu "A Good Man Is Hard to Find" para aparecer em seu texto historicista de literatura para a faculdade, American Literary Record. No começo da década de 1970, a maioria das antologias de literatura americana incluía contos de O'Connor. A pesquisa de Paul Lauter de 1982 sobre cinquenta cursos introdutórios à literatura americana em faculdades descobriu que O'Connor era a única escritora contemporânea mulher a aparecer nessas listas [de antologias] ${ }^{15}$ (FODOR, 1996, p. 13-14, tradução nossa).

O’Connor figurava no currículo de quatro cursos introdutórios. Apenas quatro outras escritoras eram incluídas em currículos: Emily Dickinson, que aparecia em vinte cursos, Wharton, em oito, Chopin, em oito, Jewett, em seis, e Bradstreet, em seis. Já em 1988, O’Connor tornou-se uma das poucas mulheres a ser incluída na série de coletâneas da Library of America, "que chama a si mesma de 'a única coleção definitiva dos maiores escritores da America”" (FODOR, 1996, p.14, tradução nossa), com a publicação de seus Collected Works (1988), que inclui seus dois romances, todos os contos publicados, um trecho de seu romance inacabado Why

\footnotetext{
14 "hostile, but the mere fact that O'Connor was reviewed in prestigious journals like the Kenion Review and in influential mass circulation magazines like Time indicates that critics saw her as a writer who had to be taken seriously, if not necessarily admired".

15 “Willard Thorpe chose 'A Good Man Is Hard to Find' to appear in his historicista college literature text, American Literary Record. By the early 1970s, most American literature anthologies included O'Connor's stories. Paul Lauter's 1982 survey of fifty American literature college introductory courses found that O'Connor was the only contemporary woman writer to appear on these lists".
} 
Do the Heathen Rage?, alguns ensaios e cartas. Antes dela, apenas Edith Wharton (1862-1937) e Willa Cather (1873-1947) haviam sido publicadas na série. Com isso, O'Connor tornou-se a primeira escritora do século XX a ser publicada pela Library of America e juntou-se a um grupo seleto de escritores, que inclui Jack London, Eugene O'Neil e William Faulkner.

No início, os críticos classificavam a ficção de O'Connor como regionalista, colocando-a ao lado de nomes como Faulkner, Caldwell e McCullers na "escola do grotesco sulista" (FODOR, 1996). Ao fazê-lo, a crítica procurava interpretar o trabalho de O'Connor e estabelecer uma relação de importância entre sua obra e o renascimento da literatura do Sul. Conforme nos informa Fodor:

\begin{abstract}
A aliança com Caldwell enfatiza a ruralidade grotesca, sórdida, bem como questóes sociais e econômicas na sua escrita. Citar McCullers liga O'Connor a uma escritora mulher do grotesco. Nomear Faulkner faz uma reivindicação maior, porque eventos recentes haviam estabelecido a reputação de Faulkner como uma figura literária "séria" na academia (FODOR, 1996, p. 22, tradução nossa).
\end{abstract}

Assim, a identidade regional de O'Connor tornou-se um aspecto fundamental na compreensão de sua obra, durante toda a sua carreira literária. $\mathrm{O}$ regionalismo era uma maneira de inserir a autora numa tradição com a qual a sua obra poderia contribuir. A religiosidade foi outro traço marcante apontado nas resenhas, principalmente após a publicaçáo de seus dois primeiros livros, em alguns casos, como forma de diminuir a importância regionalista da autora.

Para parte dos críticos, a religiosidade era a evidência cabal de que O’Connor não seria uma "mera" escritora regional, mas sim universal e, já em 1977, Golden e Sullivan apontavam para essa tendência ao discutir a obra de O'Connor em seu aspecto religioso. De acordo com eles, a principal discussão crítica girava em torno dos objetivos religiosos autodeclarados da autora e sua realização na ficção, como demonstra o título da primeira tese de doutorado a mencionar O'Connor em 1961: The Theme of Guilt and Redemption in the Post-Second-War American Novel, de Jonathan Baumbach. Assim, embora reconheçam a existência de divergências entre os críticos, os autores dividiram, de forma simplificada, quatro principais "escolas" críticas da obra de O'Connor: 
A primeira escola aceita as intençóes religiosas de O'Connor como cumpridas em sua obra e aceita sua visão religiosa como uma visão penetrante da vida humana. [...] A segunda escola também aceita a intenção religiosa de O'Connor como cumprida em sua ficção, mas questiona a adequação de sua visão religiosa, com frequência achando-a excessivamente negativa e anti-humanista. [...] A terceira escola admite que a intençấo religiosa de O'Connor tem certa relevância em sua ficção, mas questiona quáo plenamente essa intenção é atingida em sua obra. [...] A quarta escola nega a intenção religiosa completamente, preferindo ler seu trabalho de várias outras maneiras (GOLDEN, SULLIVAN, 1977, p. 5-6, tradução nossa).

De acordo com eles, as primeiras críticas de O'Connor seguiam a quarta escola e, somente com sua maior divulgação e com as próprias afirmaçōes da autora sobre sua visão religiosa, as outras escolas se desenvolveram. Ainda assim, até a década de 1970, a maior parte dos textos escritos seguia a primeira e a segunda escolas. Essas "escolas", na realidade, devem ser encaradas mais como abordagens, já que há críticos que transitam entre elas, frequentemente combinando elementos de abordagens religiosas com abordagens não religiosas.

Além do regionalismo e da religiosidade, logo de início, muitos comentários sobre a obra de O'Connor descreviam seu estilo como "masculino" e "pouco feminino". Esse tipo de afirmação classificava a obra da autora como oposta àquilo que se esperaria de uma mulher, e foi muito usada em sua divulgaçáo, "para explicar o poder que os leitores percebiam em sua ficção e para reivindicar uma audiência mais ampla para seu trabalho" (FODOR, 1996, p. 25, tradução nossa).

Estes mesmos traços (regionalismo, religiosidade e masculinidade), no entanto, foram usados para criticar a obra de O'Connor. Os periódicos Time e New Yorker, por exemplo, publicaram apenas resenhas curtas e negativas enquanto O'Connor ainda estava viva. Em uma resenha de The Violent Bear It Away, publicada no Time, o autor utiliza dados biográficos da autora como sua doença e vida retirada em Andalusia para desmerecer o romance (FODOR, 1996). O autor aponta ainda para o fato de que O'Connor era católica ferrenha, solteira, criava aves e andava de muletas, como para sustentar sua posição de que O'Connor era tão grotesca quanto suas personagens e não se poderia esperar dela outro tipo de ficção.

Apenas após a publicação de seu segundo romance e de sua morte, em 1964, os críticos passaram a explorar outros aspectos de sua ficçấo, especialmente seu tratamento para o período contemporâneo à autora. 
Golden e Sullivan (1977, p. 4-5, tradução nossa) apontam que, desde a morte de O'Connor até 1977, foram publicados "dezoito livros dedicados exclusivamente à sua ficção e sessenta e cinco teses de doutorado que discutem suas obras". Os primeiros livros mencionados são de 1966: Flannery O'Connor: A Critical Essay, de Robert Drake; The Added Dimension: The Art and Mind of Flannery O'Connor, de Mervin Friedman e Lewis A. Lawson e Flannery O'Connor, de Stanley Edgar Hyman, que é, na verdade, um panfleto didático de uma série de pequenos guias para a obra de escritores americanos.

Fodor também comenta a grande atenção crítica recebida pela obra de O'Connor, após sua morte, e, especialmente, com a publicação de seu segundo livro de contos, Everyhting That Rises Must Converge, em 1965. De acordo com ela, no início da década de 1970, O’Connor estava no topo da lista dos temas de teses de doutorado sobre escritores posteriores a 1930 (FODOR, 1996, p. 33, traduçáo nossa), mas foi, principalmente, a partir dos anos oitenta que as abordagens críticas começaram a se multiplicar, quando apareceram estudos psicanalíticos (Frederick Asals), feministas (Louise Westling), bakhtinianos (Bruce Gentry e Robert Brinkmeyer) e lacanianos (James Mellard).

Teresa Caruso (2004) acredita que o interesse tardio da crítica feminista em Flannery O'Connor deva-se, em parte, aos seus objetivos religiosos autodeclarados, que guiaram, em grande medida, os estudos críticos. Em seu guia, Golden e Sullivan (1977) nem chegaram a incluir a entrada "feminismo" no index. O Flannery O'Connor: An Annotated Reference Guide, que compreende todas as publicaçóes acerca da autora, de 1975 a 2000 (e mençóes a livros de anos anteriores), traz apenas 38 mençóes a trabalhos sobre o tema "feminismo" durante o período.

O primeiro livro a explorar esse aspecto da obra de O'Connor foi Sacred Groves and Ravaged Gardens: the fiction of Eudora Welty, Carson McCullers and Flannery O'Connor, de Louise Westling, em 1985. Apesar de inovadora, a obra de Westling ainda defende que, na obra de O'Connor, os homens são representados como agressivos e vingativos, enquanto as mulheres são punidas e tornadas passivas pelos homens. Além desse, apenas um livro de crítica feminista sobre O'Connor foi publicado até o ano 2000; após essa data, encontramos mais dois: Revising Flannery O'Connor (2001), de Katherine Prown e "On the subject of the feminist business" (2004), organizado por Teresa Caruso. Outros estudiosos que deram importância à questão feminista foram Richard Giannone, Claire Kahane, que destacou 
o aspecto psicanalítico e gótico, e Katherine Prown, que, em um artigo de 1995, defendeu que houve uma "feminização" dos protagonistas homens nos dois romances da autora.

Os primeiros comentários feministas sobre a autora parecem sempre pender para a afirmaçáo de que O'Connor compactuava com os valores masculinos. Essa tendência crítica ainda é bastante forte, como artigos publicados em "On the subject of the feminist business" deixam transparecer. Teresa Caruso (2004, p. 6, tradução nossa), a organizadora do volume, por outro lado, argumenta que, embora a abordagem religiosa seja profícua, as "maneiras 'antigas' de olhar para a obra de O'Connor são insuficientes: ela exige mais dos seus leitores", e a abordagem feminista pode ser uma maneira de mantê-la relevante no âmbito da literatura norte-americana.

Talvez devido à grande ênfase dada às interpretaçóes religiosas e ao pequeno número de críticas feministas, alguns contos da autora, como " $A$ Stroke of Good Fortune" e "A View of the Woods", considerados por Prown (2001) como os mais engajados com o "ponto de vista feminino", tenham recebido pouca atenção da crítica quando comparados a outros contos mais célebres. Scott (2000) traz apenas três menções a "A Stroke of Good Fortune" em livros, seis em teses de doutorado e vinte em capítulos de livros e artigos. "A View of the Woods" por sua vez, conta com quatro mençóes em livros, seis em teses e um pouco mais em textos curtos do que "A Stroke of Good Fortune", mas, ainda assim, muito menos mençóes em capítulos e artigos que "Good Country People", notadamente um dos contos mais comentados do início da carreira da autora, ao lado de "A Good Man Is Hard to Find". Contos que permitem mais abertamente interpretaçóes teológicas e filosóficas como os finais "Revelation" e "Parker's Back" foram muito mais explorados em livros e teses que os primeiros contos de O'Connor, como "A Temple of the Holy Ghost", que, ainda assim, é mais comentado que "A Stroke of Good Fortune". Todavia, a publicação de artigos e de livros que problematizam sua relação com os manuscritos e também o romance Wise Blood demonstra que esse último conto tem chamado mais a atenção da crítica após o ano 2000. As críticas feministas não só têm resgatado contos relegados a segundo plano, quanto têm também problematizado leituras tradicionais de personagens femininas de O'Connor.

Surpreendentemente, apesar de haver muitas menções no Annotated Reference Guide ao estudo do grotesco na obra de O'Connor, a maior parte delas é de capítulos de livros ou artigos. Foram publicados, até o ano 2000, apenas três livros inteiramente dedicados à investigação do tema: Nightmares 
and Visions (1972), de Gilbert H. Muller, em que aborda a relação entre a religião católica e o grotesco, Flannery O'Connor's Religion of the Grotesque (1986), de Marshall Bruce Gentry, que parte dos princípios bakhtinianos de grotesco e romance como campo de batalha; e American Gargoyles (1995), de Anthony Di Renzo, que estuda a relaçáo da obra da autora com o grotesco medieval. Há ainda um volume de 1998, de Laurence Enjouras, que defende, de forma reducionista, que a representação do corpo na obra de O'Connor é sempre como "feio" e não "respeitável", ignorando seu o potencial positivo. Ademais, existem apenas algumas teses de doutorado dedicadas ao assunto do grotesco, mas ainda assim há margem para mais exploração.

Podemos perceber que, diferentemente da maioria dos autores, Flannery O'Connor conseguiu, de alguma maneira, guiar a crítica de sua obra na direçáo religiosa segundo a qual gostaria que fosse interpretada e poucos estudiosos parecem contradizer as afirmaçôes dela sobre a própria arte. É verdade que é difícil desprezar a dimensão teológica da ficção de O'Connor; ainda assim, concordamos com Teresa Caruso (2004, p. 11, tradução nossa), quando ela afirma que "enquanto a orientaçáo espiritual certamente oferece uma base válida e fértil para a crítica teológica, para muitos leitores essas interpretaçóes teológicas há muito falharam em fornecer entendimento completo (ou, eu argumentaria, satisfatório) de seus contos".

\section{Consideraçóes finais}

Conforme demonstrado ao longo deste artigo, Flannery O'Connor, assim como suas colegas escritoras, enfrentou oposição da crítica, especialmente dos adeptos do New Criticism, por ser mulher e ousar escrever. Para os homens de letras das décadas de quarenta e cinquenta, a mulher ainda deveria ser apenas a musa inspiradora, o objeto da arte. Portanto, a atitude de uma mulher decidir por escrever, já era, por si só, considerada grotesca. Grotesca também era a posição ambivalente ocupada por escritoras como O'Connor no movimento do New Criticism, pois, embora fossem publicadas, não eram respeitadas enquanto autoridades literárias. Conforme afirmam Gilbert e Gubar, retomando Anne Finch:

\footnotetext{
Uma "mulher que se lança à caneta" não é apenas uma "criatura pretensiosa" e intrusa, ela é absolutamente irremissível: nenhuma virtude pode superar a "falha" de sua presunção, porque ela cruzou de forma grotesca os limites
} 
Bem como suas personagens, Flannery O'Connor era vista como uma "aberração" pelos críticos contemporâneos e pelo público. Talvez seja por isso que a autora tenha tomado a decisão de parar de assinar como "Mary Flannery O'Connor", optando por um nome que não é explicitamente gendrado, enquanto ainda era aluna em Iowa, pois é muito possível que essa escolha tenha lhe rendido maiores chances de ter seus manuscritos lidos e publicados.

Se toda ficção escrita por mulheres é um discurso de duas vozes (SHOWALTER, 1994, p. 50), o discurso de O'Connor, além de estar contido na cultura dominante, possui um lado que está contido na "zona selvagem" (SHOWALTER, 1994) das mulheres. Porém, muitos críticos parecem apressados em perceber apenas a reprodução da tradição patriarcal ocidental e desmerecem o papel da zona selvagem, rotulando apressadamente a ficção de uma mulher como se fosse algo mais simples de ser compreendido e decifrado do que a ficção produzida por homens.

Ignorar uma das vozes do discurso de O'Connor significa marginalizar o discurso feminino e calar autoritariamente a faceta subversiva de sua obra, inerente ao uso do grotesco. É curioso que, mesmo décadas após a morte de O'Connor, sua obra ainda contribua não apenas para lançar luz sobre as limitaçôes e contradiçôes da sociedade, mas também sobre as limitaçóes e o preconceito dos estudos críticos literários que, com frequência, rotulam as produções de mulheres como "panfletárias" e, por isso, inferiores; ou como semelhantes à literatura "masculina" e, por isso, não engajadas.

\section{Referências}

CARUSO, Teresa (Org.). On the subject of the feminist business: rereading Flannery O'Connor. New York: Peter Lang, 2004.

FODOR, Sarah J. Marketing Flannery O'Connor: Institutional Politics and Literary Evaluation. In: RATH, Sura P.; SHAW, Mary Neff. (Ed.). Flannery O'Connor: New Perspectives. Athens and London: University of Georgia Press, 1996. p. 12-37.

GILBERT, Sandra M.; GUBAR, Susan. The Madwoman in the Attic: The Woman Writer and the Nineteenth Century Literary Imagination. 2. ed. 
New Haven and London: Yale University Press, 2000.

GOLDEN, Robert E.; SULLIVAN, Mary C. Flannery O'Connor and Caroline Gordon: A Reference Guide. Boston: G. K. Hall \& Co., 1977.

GORDON, Sarah. Flannery O'Connor: The Obedient Imagination. Athens. Georgia: University of Georgia Press, 2000.

HENDIN, Josephine. The World of Flannery O'Connor. Bloomington and London: Indiana University Press, 1970.

JORDAN, Michael M. Flannery O'Connor's Writing: A Guide for the Perplexed. In: Modern Age, Winter, p. 48-57, 2005. Disponível em: <http://www.mmisi.org/ma/47_01/jordan.pdf>. Acesso em: 1 nov. 2011.

O'CONNOR, Flannery. A Stroke of Good Fortune. Shenandoah. v. 4. n.1, p. 7-18, 1953.

. Collected Works. New York: The Library of America, 1988.

. Contos completos: Flannery O’Connor. Trad. Leonardo Fróes. São Paulo: Cosac Naify, 2008.

Lecture on the grotesque in Southern fiction. 1962; 1963. Localizado em: Special Collections, Ina Dillard Russel Library, Georgia College and State University, Milledgeville, GA, Arquivos 247-249.

. Some Aspects of the Grotesque in Southern Fiction. 1960. Localizado em: Special Collections, Ina Dillard Russel Library, Georgia College and State University, Milledgeville, GA, Arquivos 245-246.

. The Freak in Modern Fiction. s/d. Localizado em: Special Collections, Ina Dillard Russel Library, Georgia College and State University, Milledgeville, GA, Arquivos 243-244.

PROWN, Katherine Hemple. Revising Flannery O'Connor: southern literary culture and the problem of female authorship. Charlottesville and London: University Press of Virginia, 2001. 
SCOTT, Neil R. Flannery O'Connor: An Annotated Reference Guide to Criticism. Milledgeville: Timberlane, 2002.

SHOWALTER, Elaine. A crítica feminista no território selvagem. In: HOLLANDA, Heloísa Buarque de (Org). Tendências e Impasses: o Feminismo como crítica da Cultura. Rio de Janeiro: Rocco, 1994. p. 23-57.

WARREN, Nagueyalti. Introduction to Alice Walker's "Convergence". Flannery O’Connor Review. v. 12, p. 1-2, 2014.

YAEGER, Patricia. Dirt and Desire: Reconstructing Southern Women's Writing, 1930-1990. Chicago: The University of Chicago Press, 2000. 